\title{
CUSTO E LUCRO DA PRODUÇÃO DE CANOLA E MILHO NOS ESTADOS UNIDOS DA AMÉRICA E BRASIL
}

\section{COST AND PROFIT OF CANOLA AND MAIZE PRODUCTION IN THE UNITED STATES OF AMERICA AND BRAZIL}

\author{
Luiz Cláudio Garcia* \\ ORCID: https://orcid.org/0000-0001-6378-2829 \\ Adenilson Mroginski de Souza** \\ ORCID: https://orcid.org/0000-0001-5091-1126 \\ Hendrik Albert Barkema*** \\ ORCID: https://orcid.org/0000-0001-6185-8463 \\ Felipe Santos Baldim**** \\ ORCID: https://orcid.org/0000-0002-7189-4334 \\ Pedro Henrique Weirich Neto***** \\ ORCID: https://orcid.org/0000-0002-9039-102X \\ Carlos Hugo Rocha****** \\ ORCID: https://orcid.org/0000-0001-5035-2643
}

Data recebimento: 01/09/2020

Data de aceite: 07/04/2021

\section{Resumo}

Na Universidade Estadual de Ponta Grossa (UEPG), dentre as atividades de extensão que promovem a interação entre alunos e a comunidade está o The Ohio Program, iniciado em 1979 para atender aos acadêmicos que buscam a experiência internacional. No intuito de retornar um trabalho sistematizado às comunidades que lhes acolheram, os extensionistas tiveram como desafio escolhido pelos agricultores comparar o custo e lucro de se produzir canola (Brassica napus var oleifera) e milho (Zea mays) nos Estados Unidos da América (EUA) e no Brasil. A canola teve como base de comparação os estados de Dakota do Norte (EUA) e Paraná (Brasil) na safra 2012. Já o milho teve dados coletados nos estados do Kansas (EUA) e Paraná, na safra 2016/17. O custo e a produtividade da canola foram maiores nos EUA, contudo, o lucro mais elevado foi alcançado em terras brasileiras. Em se tratando de milho, o custo, produtividade e lucro forma mais elevados no Brasil. Destaca-se a vocação agrícola brasileira e a necessidade da extensão rural que contemple as peculiaridades do meio agropecuário, superando barreiras geográficas e de idiomas.

Palavras-chave: Brassica napus var oleifera. Extensão Universitária Internacional. Produtividade. Zea mays.

\section{Abstract}

At the State University of Ponta Grossa (UEPG), among the extension activities that promote interaction between students and the community is The Ohio Program, started in 1979 to support students seeking international experience. In order to return a systematic study to the communities that welcomed them, the extensionists were challenged by farmers to compare the cost and profit of producing canola (Brassica napus var oleifera) and corn (Zea mays) in the United States of America (USA) and in Brazil. The 2012 canola harvest numbers in the states of North Dakota (USA) and Paraná (Brazil) were compared, while the corn data was collected in the states of Kansas (USA) and Paraná in the 2016/17 harvest. Canola cost and productivity were higher in the USA, however higher profit was achieved on Brazilian land. Regarding corn, higher cost, productivity and profit occurred in Brazil. Our results highlight the Brazilian agricultural vocation and the need for rural extension that includes the peculiarities of the agricultural environment, overcoming geographical and language barriers.

Keywords: Brassica napus var oleifera. International University Extension. Productivity. Zea Mays.

* Professor da Universidade Estadual de Ponta Grossa (UEPG), Ponta Grossa - PR, Brasil. E-mail: lcgarcia@uepg.com

** Engenheiro Agrônomo. Universidade Estadual de Ponta Grossa (UEPG), Ponta Grossa - PR, Brasil. E-mail: adenilsonmdesouza@gmail.com

*** Engenheiro Agrônomo. Universidade Estadual de Ponta Grossa (UEPG), Ponta Grossa - PR, Brasil. E-mail: hendrikbarkema@gmail.com

**** Engenheiro Agrônomo. Universidade Estadual de Ponta Grossa (UEPG), Ponta Grossa - PR, Brasil. E-mail: felipebaldim02@gmail.com

***** Professor da Universidade Estadual de Ponta Grossa (UEPG), Ponta Grossa - PR, Brasil. E-mail: lama1@uepg.br

****** Professor da Universidade Estadual de Ponta Grossa (UEPG), Ponta Grossa - PR, Brasil. E-mail: chrocha@uepg.br 


\section{Introdução}

Ao promover a edificação de conhecimento e ao se constituir como elemento capaz de operacionalizar a relação entre teoria e prática, a extensão se torna uma fonte de integração na relação ensino-pesquisa. Essa concepção de integração das atividades desenvolvidas no campo acadêmico está estabelecida na Constituição de 1988, no seu artigo 207, com a presença indissociável do ensino, da pesquisa e da extensão como um dos aspectos que fundamentam a universidade. O princípio da indissociabilidade das atividades de ensino, pesquisa e extensão é fundamental no fazer acadêmico (SANTOS et al., 2016).

Os desafios da extensão universitária são impostos aos acadêmicos envolvidos no processo. Em seu estudo, Oliveira et al. (2016) destacam as dificuldades da atividade: timidez, estabelecimento da linguagem diferente da acadêmica para uma boa comunicação com o público, alteração dos costumes da comunidade, transporte, apoio financeiro às ações extensionistas, a capacidade de conquistar a confiança das comunidades e a continuidade das ações extensionistas a longo prazo.

Nesse contexto, ao transformar informação em conhecimento, os acadêmicos exploraram os três pilares da Educação Superior Brasileira, com a análise dos resultados em conjunto com as pessoas envolvidas; reforça-se o importante espaço de formação e de aproximação entre a universidade e a complexidade da sociedade, com suas peculiaridades técnicas, ambientais e socioculturais. Ao atingir os objetivos da extensão universitária, todos se beneficiam das ações - alunos e comunidade -, contribuindo, na mais das vezes, para o desenvolvimento sustentável em diferentes esferas do conhecimento (NEVES et al., 2019).

Ao destacar a complexidade do meio rural, Schlindwein et al. (2015) ressaltam a exigência de uma extensão rural que contemple as peculiaridades do meio agropecuário. Desta forma, ações extensionistas proporcionam a interação de conhecimentos entre os agricultores e as instituições, auxiliando na aplicação de técnicas, na gestão e na comercialização da produção.

$\mathrm{Na}$ Universidade Estadual de Ponta Grossa (UEPG), dentre as atividades que promovem a interação entre alunos e a comunidade está o The Ohio Program. O programa, em parceria com a Ohio State University, iniciou em 1979 para atender aos acadêmicos que buscam a experiência internacional. Os estudantes do curso de Engenharia Agronômica da UEPG têm participado ativamente do programa na frequência em aulas oferecidas pela Ohio State University, pesquisa na produção de plantas ornamentais em casas de vegetação e manejo técnico investigativo das culturas nas propriedades rurais dos Estados Unidos da América (EUA). As culturas com destaque naquela região são a canola, o milho e a soja (ERI, 2019; GARCIA et al., 2019).

A canola (Brassica napus var oleifera) foi desenvolvida através do melhoramento da espécie colza, ocupando a ordem de segunda oleaginosa de importância mundial. Por pertencer à família das Crucíferas, favorece a estratégia de rotação de culturas, apresenta resistência ao frio e oportuniza uma fonte adicional de renda ao agricultor. Atualmente, é adotada como fonte de óleo vegetal e proteína, sendo ainda empregada na indústria para produção de biodiesel e farelo para rações (KAEFER et al., 2014; WANASUNDARA et al., 2016). 
Os EUA, em 2011 - safra que abrange o período de estudo deste artigo , produziram 780 mil toneladas, com uma média de produtividade de $1.853 \mathrm{~kg} \mathrm{ha}^{-1} \mathrm{e}$ área plantada de 421 mil hectares. Os maiores limitantes na produção de canola estão no pequeno espaço de tempo que os produtores têm para colher a cultura e a ocorrência da doença mofo-branco (Sclerotinia sclerotiorum), o que restringe as opções na rotação de culturas por se propagar em vários gêneros de plantas (USDA, 2012).

No Brasil, na safra 2011, a área de canola semeada foi de 49 mil hectares, com média de produtividade de $1.509 \mathrm{~kg} \mathrm{ha}^{-1}$, totalizando 73 mil toneladas de produção (CONAB, 2012). É cultivada no período de outono/inverno, pelo fato de apresentar baixa sensibilidade a fotoperíodo e não necessitar de elevada vernalização, com algumas limitações no sistema de produção a serem superadas para que haja redução de perdas e aumento na produtividade (EMBRAPA, 2019). Dentre os principais entraves, encontram-se a dificuldade na semeadura, falta de herbicidas com seletividade à cultura, susceptibilidade a pragas e doenças principalmente o mofo-branco - e as elevadas perdas na colheita relacionadas à maturação desuniforme da planta e deiscência natural de síliquas (MAINARDES et al., 2018).

A cadeia produtiva do milho (Zea mays) é mais solidificada que a da canola, em ambos os países, tendo como desafio superar a ocorrência de micotoxinas e o custo do transporte. $\mathrm{O}$ Brasil é o terceiro maior produtor mundial de milho, ficando atrás dos EUA e China, que estão em primeiro e segundo lugar, respectivamente. Na safra 2016/17 - momento em que a pesquisa foi desenvolvida - a produtividade média brasileira foi de $5.471 \mathrm{~kg} \mathrm{ha}^{-1}$, com produção de 93 milhões de toneladas em cerca de 17 milhões de hectares (CONAB, 2017). Já a produção de milho, no ano de 2016, nos EUA, foi de 354 milhões de toneladas, sendo cultivados cerca de 35 milhões de hectares, perfazendo uma produtividade média de $10.114 \mathrm{~kg} \mathrm{ha}^{-1}$ (USDA, 2017).

Sendo assim, o objetivo da ação extensionista foi comparar os custos de produção e desafios enfrentados na produção de canola e milho no Brasil e nos EUA, a fim de estudar, com as comunidades envolvidas, estratégias para superar os desafios impostos em cada cultura.

\section{Método}

A pesquisa foi desenvolvida por acadêmicos de Engenharia Agronômica que participaram do The Ohio Program, convênio entre a Universidade Estadual de Ponta Grossa (UEPG) e a Ohio State University (ERI, 2019; GARCIA et al., 2019). A motivação do estudo foi a necessidade de os alunos retornarem um trabalho sistematizado às comunidades que thes acolheram. Os estudantes de Agronomia tiveram como desafio escolhido pelos agricultores comparar o custo e lucro de se produzir canola e milho nos EUA e no Brasil.

Os valores empregados na produção, produtividade e lucro da canola no estado da Dakota do Norte $\left(47^{\circ} 44^{\prime} \mathrm{N}\right.$ e $\left.102^{\circ} 02^{\prime} \mathrm{W}\right)$, com clima semiárido frio, foram levados em consideração para se chegar no investimento realizado nos EUA (Figura 1). No Brasil, o sistema de produção e comercialização da canola na região dos Campos Gerais $\left(25^{\circ} 05^{\prime} \mathrm{S}\right.$ e 
$50^{\circ} 10^{\prime} \mathrm{O}$ ), clima temperado, com verão ameno, no estado do Paraná (Figura 2), foram a base dos cálculos. A safra de acompanhamento foi a de 2012.

Já para a cultura do milho, tomaram-se os investimentos e lucro da safra 2016 na cidade de Colby, clima continental úmido, de verão quente, com georreferencia $39^{\circ} 20^{\prime} \mathrm{N}$ e $101^{\circ} 8^{\prime} \mathrm{O}$ (Figura 3), no estado do Kansas (EUA). No Brasil, a região dos estudos foi focada no município de Carambeí (Figura 4), região dos Campos Gerais $\left(25^{\circ} 05^{\prime} \mathrm{S}\right.$ e $\left.50^{\circ} 10^{\prime} \mathrm{O}\right)$, no estado do Paraná (Brasil), safra 2016/17.

A lacuna entre as safras onde os dados foram coletados se deu pelo período em que houve o intercâmbio dos alunos do curso de Engenharia Agronômica da UEPG participantes do The Ohio Program. A cultura escolhida em cada época foi decidida pela representatividade na região onde os estudantes atuavam nos EUA e Brasil.

A tabulação dos dados foi realizada levando-se em consideração todos os custos fixos e variáveis, calculando-se as respectivas porcentagens de participação de cada item no preço total de produção em dólares (US\$) e real (R\$). Também foram levantados as produtividades médias e respectivos preços pagos pelas culturas, tanto nas propriedades (três propriedades por cultura em cada país) como nos órgãos oficiais nos EUA e Brasil, para se calcular o lucro das culturas nos países em estudo.

Figura 1 - Canola (Brassica napus var oleifera) cultivada no estado da Dakota do Norte (EUA), safra 2012.

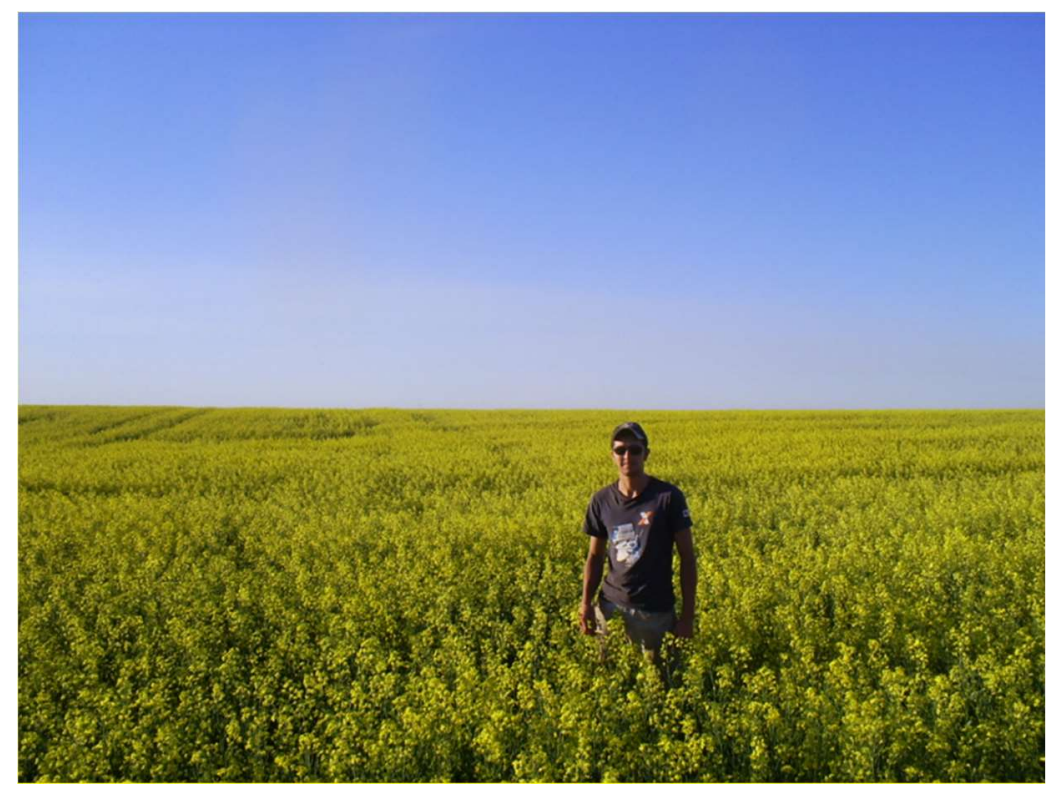

Fonte: Adenilson Mroginski de Souza.

Os agricultores, estudantes e professores envolvidos no projeto do The Ohio Program, convênio entre a Universidade Estadual de Ponta Grossa (UEPG) e a Ohio State University, tiveram acesso aos dados. A análise conjunta dos valores levantados se deu através de relatórios e apresentações em reuniões. 
Figura 2 - Canola (Brassica napus var oleifera) cultivada no estado do Paraná (Brasil), safra 2012.

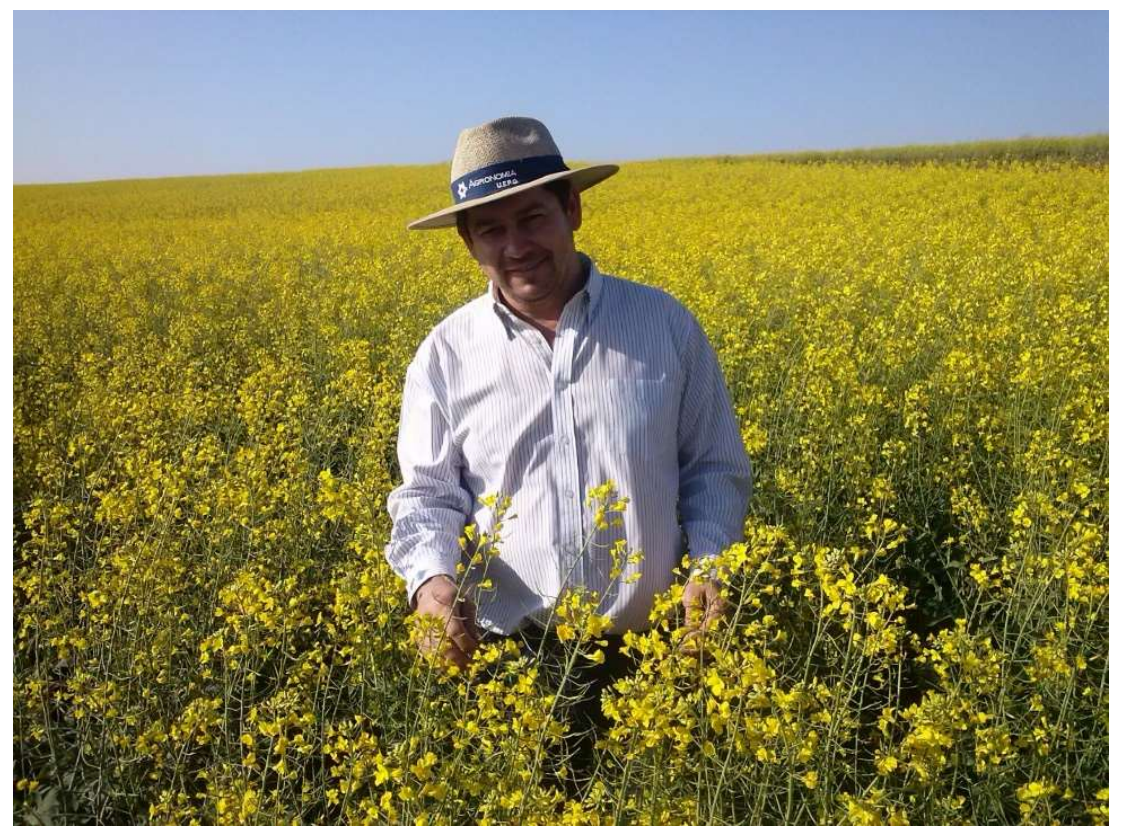

Fonte: Luiz Cláudio Garcia.

Figura 3 - Milho (Zea mays) cultivado no estado do Kansas (EUA), safra 2016.

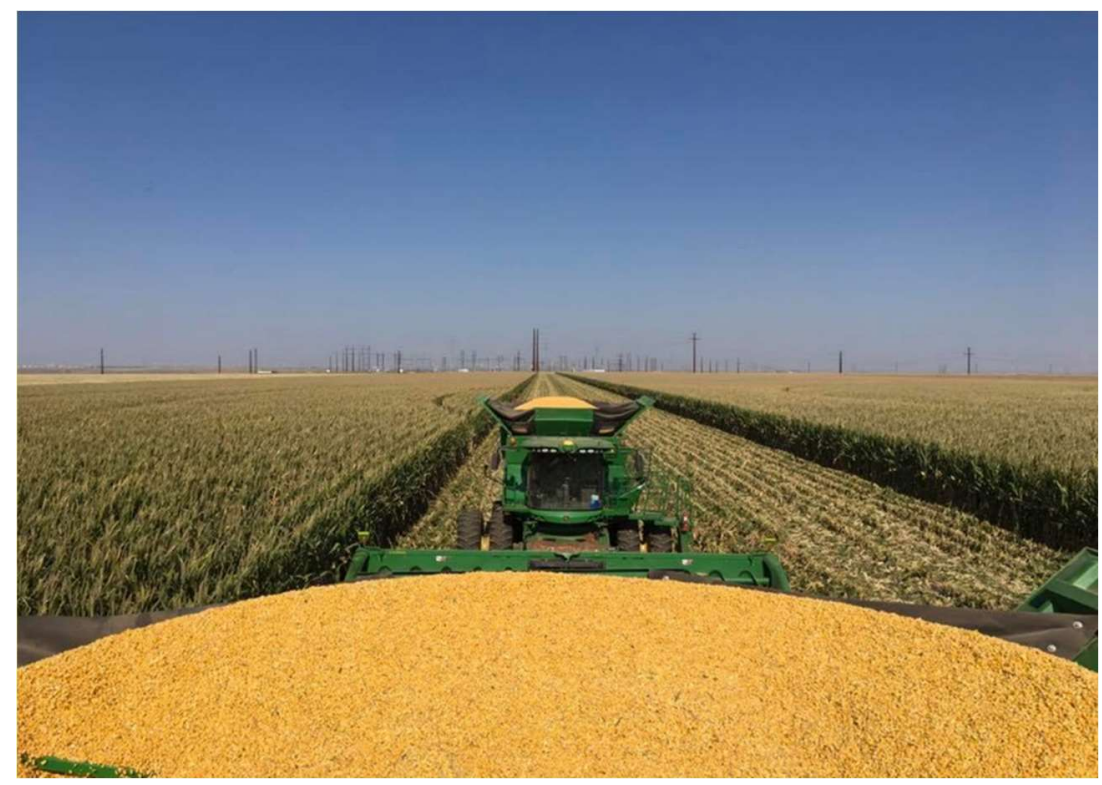

Fonte: Jordan Taylor. 
Figura 4 - Milho (Zea mays) cultivado no estado do Paraná (Brasil), safra 2016/17.

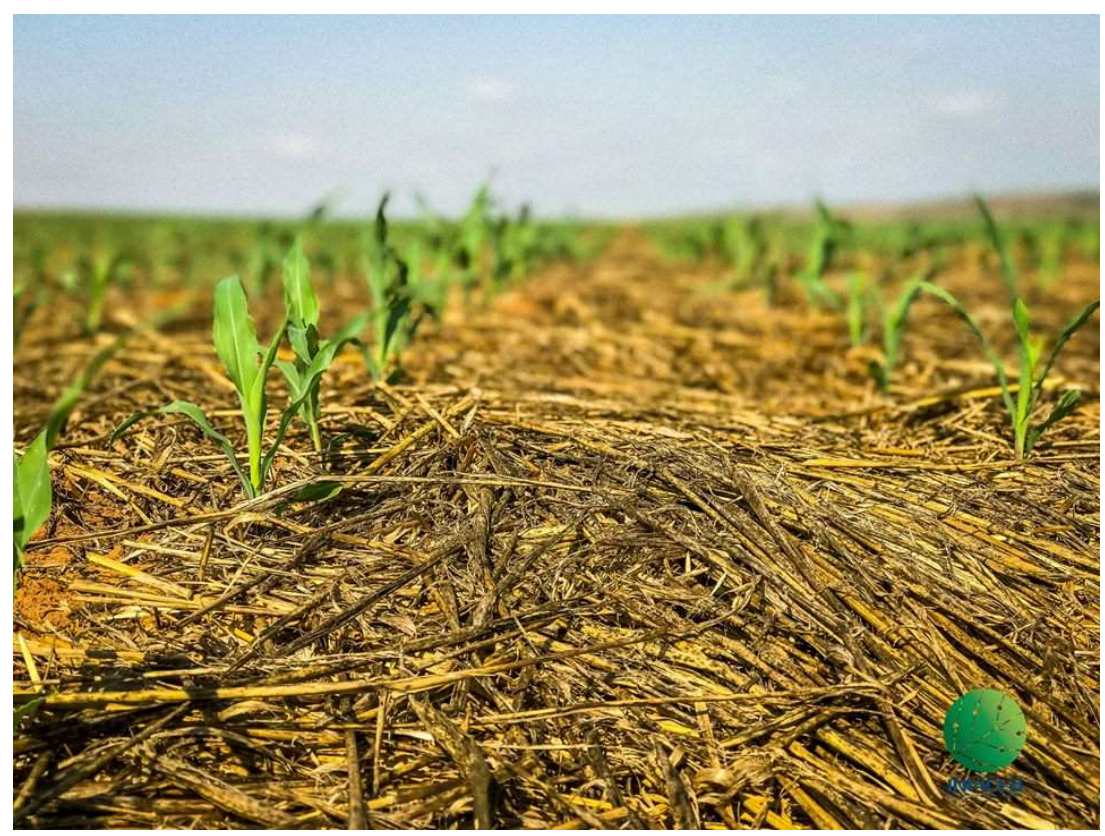

Fonte: Invicta Consultoria em Agronegócio.

\section{Resultados}

A coleta de informações, análise dos dados e divulgação dos resultados envolveram os agricultores das regiões escolhidas para a investigação no EUA e Brasil. Desta forma, a participação da comunidade foi preponderante na determinação das similaridades e diferenças da mesma cultura, na singularidade de cada local. Concordam-se, assim, com Schlindwein et al. (2015), ao ressaltarem a exigência de uma extensão rural que contemple as peculiaridades do meio agropecuário.

Ao se analisarem os custos para produção de canola nos EUA (Tabela 1) e no Brasil (Tabelas 2), destacase que a quantidade de sementes distribuídas no Hemisfério Sul é 2,2 vezes menor. Tal fato pode ser atribuído à tecnologia embarcada nas semeadoras que qualificam a distribuição de sementes tão pequenas, em média, inferiores a 5,0 mm de diâmetro, no Brasil, o que não foi identificado no estado de Dakota do Norte. 
Tabela 1 - Custos da produção da canola (Brassica napus var oleífera) cultivada no estado da Dakota do Norte (EUA), safra 2012.

\begin{tabular}{|c|c|c|c|c|c|}
\hline \multirow{2}{*}{\multicolumn{2}{|c|}{ Descrição }} & \multirow{2}{*}{$\begin{array}{c}\text { Quantidade } \\
\text { kg ha }^{-1}\end{array}$} & \multicolumn{2}{|c|}{ Preço $^{4}$} & \multirow{2}{*}{$\begin{array}{c}\text { Participação } \\
\%\end{array}$} \\
\hline & & & R\$ ha ${ }^{-1}$ & US\$ ha-1 & \\
\hline \multicolumn{2}{|l|}{ Sementes } & 5,6 & 233,55 & 111,21 & 13,6 \\
\hline \multirow{3}{*}{ Adubos } & Fósforo (11-52-0) & 78,5 & 119,36 & 56,84 & 6,9 \\
\hline & Enxofre $(21-0-24)^{1}$ & 89,7 & 93,54 & 44,54 & 5,4 \\
\hline & Nitrogênio ${ }^{2}$ & 123,4 & 295,82 & 140,87 & 17,2 \\
\hline \multicolumn{2}{|l|}{ Herbicida } & $3,2 \mathrm{~L} \mathrm{ha}^{-1}$ & 28,68 & 13,66 & 1,7 \\
\hline \multicolumn{2}{|c|}{ Semeadura (operação) } & - & 129,73 & 61,78 & 7,5 \\
\hline \multicolumn{2}{|c|}{ Pulverização (operação) } & - & 31,11 & 14,81 & 1,8 \\
\hline \multicolumn{2}{|l|}{ Colheita } & - & 207,67 & 98,89 & 12,1 \\
\hline \multicolumn{2}{|c|}{ Seguro da lavoura } & - & 62,30 & 29,67 & 3,6 \\
\hline \multicolumn{2}{|c|}{ Custos Variáveis } & - & $1.201,76$ & $\mathbf{5 7 2 , 2 7}$ & 69,8 \\
\hline \multicolumn{2}{|c|}{ Aluguel da terra } & - & 389,20 & 185,33 & 22,6 \\
\hline \multicolumn{2}{|c|}{ Custos indiretos $^{3}$} & - & 129,77 & 61,80 & 7,6 \\
\hline \multicolumn{2}{|c|}{ Custos fixos } & - & $\mathbf{5 1 8 , 9 7}$ & 247,13 & 30,2 \\
\hline \multicolumn{2}{|c|}{ Custo Total } & - & $1.720,73$ & 819,40 & 100,0 \\
\hline
\end{tabular}

${ }^{1}$ Enxofre aplicado na fórmula do sulfato de amônia.

${ }^{2}$ Nitrogênio é obtido pelo uso de amônia anidra $(82 \% \mathrm{~N})$.

${ }^{3}$ Inclui mão de obra contratada, seguro da fazenda, reparos, depreciação, benfeitorias etc.

${ }^{4}$ Cotação do dólar em 05/12/2012 - US\$ 1,00 = R \$ 2,10.

A adubação é o maior custo de produção em ambos os países. A exigência nutricional da crucífera impacta sobremaneira no custo de produção da cultura. Devido à adubação de sistema, característica do solo e diferença de períodos de cultivo, a adubação no Brasil fícou com custo $27 \%$ abaixo dos EUA, apesar da maior quantidade distribuída em terras brasileiras. 
Economias podem ser significativas com a adoção de ferramentas da agricultura de precisão (Índice de Vegetação por Diferença Normalizada - NDVI, taxa variável de distribuição de adubo com base em mapas de solo e produtividade, condutividade elétrica do solo e definição de zonas de manejo) para elevar a eficiência do processo (BERNARDI et al., 2015).

Tabela 2 - Custos da produção da canola (Brassica napus var oleifera) cultivada na região dos Campos Gerais, estado do Paraná (Brasil), safra 2012¹.

\begin{tabular}{|c|c|c|c|c|c|}
\hline & & Quantidade & & & Participação \\
\hline & & $\mathrm{kg} \mathrm{ha}^{-1}$ & R\$ ha-1 & US\$ hat & $\%$ \\
\hline Sementes & & 2,5 & 100,00 & 47,62 & 8,9 \\
\hline & $\mathrm{NPK}^{1}$ semeadura & 200,0 & 200,00 & 95,24 & 17,8 \\
\hline Adubos & Enxofre $(21-0-24)^{2}$ & 100,0 & 99,53 & 47,40 & 8,8 \\
\hline & NPK cobertura & 100,0 & 100,00 & 47,62 & 8,9 \\
\hline Herbicida & & $3,0 \mathrm{~L} \mathrm{ha}^{-1}$ & 15,00 & 7,14 & 1,3 \\
\hline Semeadur & (operação) & - & 60,72 & 28,91 & 5,4 \\
\hline Pulveriza & o (operação) & - & 20,45 & 9,74 & 1,8 \\
\hline Colheita & & - & 135,14 & 64,35 & 12,0 \\
\hline Seguro da & avoura & - & 35,00 & 16,67 & 3,1 \\
\hline Custos V & iáveis & - & 765,84 & 364,69 & 68,0 \\
\hline Aluguel d & terra & - & 268,33 & 127,78 & 23,8 \\
\hline Custos in & $\operatorname{etos}^{3}$ & - & 91,58 & 43,61 & 8,1 \\
\hline Custos fi & & - & 359,91 & 171,39 & 32,0 \\
\hline Custo To & & - & $1.125,75$ & 536,08 & 100,0 \\
\hline
\end{tabular}

${ }^{1}$ Combinação de nitrogênio (N), fósforo (P) e potássio (K) na formulação (20-20-20).

${ }^{2}$ Enxofre aplicado na fórmula do sulfato de amônia.

${ }^{3}$ Inclui mão de obra contratada, seguro da fazenda, reparos, depreciação, benfeitorias etc.

${ }^{4}$ Cotação do dólar em 05/12/2012 - US\$ 1,00 = R\$ 2, 10 . 
O custo do emprego de herbicidas foi quase a metade no Brasil, em comparação com os EUA. A comunidade norte-americana ressalta que o controle de plantas daninhas é um desafio naquela localidade, já que o inverno rigoroso selecionou espécies de mais difícil controle no período de primavera e verão. Inseticidas e fungicidas não foram aplicados na safra 2012 em ambos os países envolvidos no estudo, já que os organismos não desejados na lavoura ficaram com população aquém do nível de controle estipulados pelos Engenheiros Agrônomos responsáveis pelas áreas de cultivo.

$\mathrm{Na}$ operação de semeadura, o fato se repetiu, com custo nos EUA próximo do dobro do brasileiro. Máquinas maiores e com tecnologia embarcada, empregadas na agricultura norteamericana, apresentam maior impacto no custo de produção, explicando a diferença do valor do investimento entre as duas nações.

De forma não tão evidente como na semeadura, o mesmo ocorreu com a quantia investida na pulverização. $\mathrm{O}$ valor da operação da máquina para o controle de plantas daninhas foi cerca de 50\% maior nos Estados Unidos da América, porcentagem similar à operação de colheita registrada entre os dois países, contribuindo para elevar a diferença do custo dos EUA em referência ao Brasil.

O custo do seguro da lavoura é quase o dobro no hemisfério norte. Os custos com mão de obra e taxas bancárias são as causas desta discrepância, apontados pelos produtores da Dakota do Norte e do Paraná.

A somatória dos custos variáveis destacou um valor 57\% maior nos EUA, quando comparados ao Brasil. Mesmo com a cadeia produtiva para produção da canola mais solidificada no país da América do Norte, a produção da canola brasileira exige menor desembolso dos agricultores.

Com relação aos itens do custo fixo, o aluguel da terra é $45 \%$ mais caro na estrutura agrária estadunidense, valor próximo aos custos indiretos (mão de obra contratada, seguro da fazenda, reparos, depreciação, benfeitorias etc.). Concluiu-se, assim, que os custos fixos para a produção de canola no Brasil foram $44 \%$ menores que nos EUA.

A tabulação do custo total, que é a somatória de todos os itens de investimento para a produção da canola, foi $53 \%$ maior em terras norte-americanas que em brasileiras. Características agroclimáticas de cada país, peculiaridades das comunidades no que se refere à ocorrência de pragas, máquinas com tecnologia embarcada e custos da mão de obra marcaram a somatória da diferença registrada.

O maior custo de investimento resultou em produtividade maior nos EUA em $327 \mathrm{~kg}$ $\mathrm{ha}^{-1}$ superior à produtividade no Brasil, que foi de $1.538 \mathrm{~kg} \mathrm{ha}^{-1}$ (Tabela 3). Os valores são similares aos registrados na safra 2011 por instituições norte-americanas (USDA, 2012) e brasileiras (CONAB, 2012). O fato de haver cultivares desenvolvidas especialmente para as condições agroclimáticas norte-americanas é um fator preponderante para potencializar a produtividade daquela comunidade. 
Tabela 3 - Lucro pela produção da canola (Brassica napus var oleifera) cultivada no estado de Dakota do Norte (EUA) e Paraná (Brasil), safra 2012.

\begin{tabular}{cccccc}
\hline \multirow{2}{*}{ País } & Produtividade & Receita $(\mathrm{R} \$$ & Custo produção (R\$ & \multicolumn{2}{c}{ Lucro } \\
\cline { 4 - 5 } & $\left(\mathrm{kg} \mathrm{ha}^{-1}\right)$ & $\left.\mathrm{ha}^{-1}\right)^{1}$ & $\left.\mathrm{ha}^{-1}\right)$ & 19,63 & $\left(\mathrm{USS} \mathrm{ha}^{-1}\right)^{2}$ \\
\hline EUA & 1.865 & $1.740,36$ & $1.720,73$ & 9,35 \\
Brasil & 1.538 & $1.297,04$ & $1.125,75$ & 171,29 & 81,57 \\
\hline
\end{tabular}

${ }^{1}$ Preço pago por tonelada de canola nos EUA em R\$ 933,17 e no Brasil por R\$ 843,33.

${ }^{2}$ Cotação do dólar em 05/12/2012 - US\$ 1,00 = R\$ 2,10.

A receita em Dakota do Norte foi favorecida pela melhor remuneração da canola que no Paraná, com diferença de preço por tonelada de grãos em $\mathrm{R} \$ 89,84$, conquistada pela cultura ter cadeia produtiva solidificada na América do Norte. Contudo, o custo de produção elevado no estado estadunidense diluiu as vantagens destacadas, com lucro pela produção da canola em R \$ 19,63 por hectare, ficando 8,7 vezes inferior que os R $\$ 171,29$ por hectare conquistados no estado brasileiro. Apesar das limitações no sistema de produção no Brasil (EMBRAPA, 2009; MAINARDES et al., 2018), confirmam-se as vantagens de que a cultura proporciona a estratégia de cultivo da propriedade (KAEFER et al., 2014; WANASUNDARA et al., 2016).

Ao se analisar o milho com as comunidades do Kansas (EUA) e Paraná (Brasil), chegou-se aos custos de produção da cultura. Dos custos variáveis em terras norteamericanas, as sementes representam o maior investimento (Tabela 4), seguido na ordem decrescente por agrotóxicos (fungicidas, herbicidas e inseticidas), colheita e adubação. Nos agrotóxicos, o herbicida foi o agroquímico com maior impacto no custo, devido à dificuldade do controle de plantas daninhas, pela falta de rotação de culturas e seleção de plantas resistentes ao glifosato, segundo a comunidade em estudo (Figura 5).

No Brasil, os custos variáveis apresentaram ordem de desembolso pelos agricultores diferente que nos EUA (Tabela 5). O maior investimento realizado pelos produtores foi em adubo, seguido de agrotóxico, sementes e colheita. Ressalta-se que o investimento em agrotóxicos se distribui em fungicidas, inseticidas e herbicidas; já que, em um país sem inverno rigoroso e mais tropicalizado, a ocorrência de pragas e doenças é mais intenso. Ao contrário da canola, onde a cadeia produtiva é muito mais solidificada nos EUA que no Brasil, o milho apresenta tecnificação similar nos países analisados. 
Tabela 4 - Custos da produção do milho (Zea mays) cultivada no estado do Kansas (EUA), safra 2016.

\begin{tabular}{|c|c|c|c|c|c|}
\hline \multirow{2}{*}{\multicolumn{2}{|c|}{ Descrição }} & \multirow{2}{*}{$\begin{array}{c}\text { Quantidade } \\
\text { kg ha }^{-1}\end{array}$} & \multicolumn{2}{|c|}{ Preço $^{4}$} & \multirow{2}{*}{$\begin{array}{c}\text { Participação } \\
\%\end{array}$} \\
\hline & & & R\$ ha $\mathbf{h}^{-1}$ & US\$ ha-1 & \\
\hline \multicolumn{2}{|l|}{ Sementes } & 9,3 & 331,36 & 94,95 & 13,7 \\
\hline & NPK semeadura ${ }^{1}$ & 100,9 & 219,55 & 62,91 & 9,1 \\
\hline \multirow[t]{2}{*}{ Adubos } & Nitrogênio ${ }^{2}$ & 44,8 & 69,28 & 19,85 & 2,9 \\
\hline & Zinco & 0,3 & 18,44 & 5,28 & 0,8 \\
\hline \multicolumn{2}{|c|}{ Agrotóxicos } & - & 320,84 & 91,93 & 13,2 \\
\hline \multicolumn{2}{|c|}{ Semeadura (operação) } & - & 155,16 & 44,46 & 6,4 \\
\hline \multicolumn{2}{|c|}{ Pulverização (operação) } & - & 103,44 & 29,64 & 4,3 \\
\hline \multicolumn{2}{|l|}{ Colheita } & - & 296,88 & 85,07 & 12,3 \\
\hline \multicolumn{2}{|c|}{ Seguro da lavoura } & - & 224,12 & 64,22 & 9,3 \\
\hline \multicolumn{2}{|c|}{ Custos Variáveis } & - & $1.739,12$ & 498,32 & 71,8 \\
\hline \multicolumn{2}{|c|}{ Aluguel da terra } & - & 474,08 & 135,84 & 19,6 \\
\hline \multicolumn{2}{|c|}{ Custos indiretos $^{3}$} & - & 209,04 & 59,90 & 8,6 \\
\hline \multicolumn{2}{|c|}{ Custos fixos } & - & 683,12 & 195,74 & 28,2 \\
\hline \multicolumn{2}{|c|}{ Custo Total } & - & $2.422,44$ & 694,11 & 100,0 \\
\hline
\end{tabular}

${ }^{1}$ Combinação de nitrogênio $(\mathrm{N})$, fósforo $(\mathrm{P})$ e potássio $(\mathrm{K})$ na formulação (00-50-50).

${ }^{2}$ Nitrogênio é obtido pelo uso de amônia anidra $(82 \% \mathrm{~N})$.

${ }^{3}$ Inclui mão de obra contratada, seguro da fazenda, reparos, depreciação, benfeitorias etc.

${ }^{4}$ Cotação do dólar em 05/12/2016 - US\$ 1,00 = R\$3,49.

Destaca-se a menor quantidade de sementes e adubos distribuídos por área norteamericana que em solo brasileiro. As diferenças das recomendações agronômicas estão baseadas no nível de investimento econômico que as particularidades de solo e clima podem rentabilizar em cada estado. 
As operações com máquinas agrícolas para semeadura, pulverização e colheita do milho são mais caras no Kansas que no Paraná. Máquinas maiores e com tecnologia embarcada elevaram o investimento em mecanização agrícola em $20 \%$.

Figura 5 - Agricultores do estado do Kansas (EUA) e alunos do curso de Engenharia Agronômica da Universidade Estadual de Ponta Grossa (PR - Brasil).

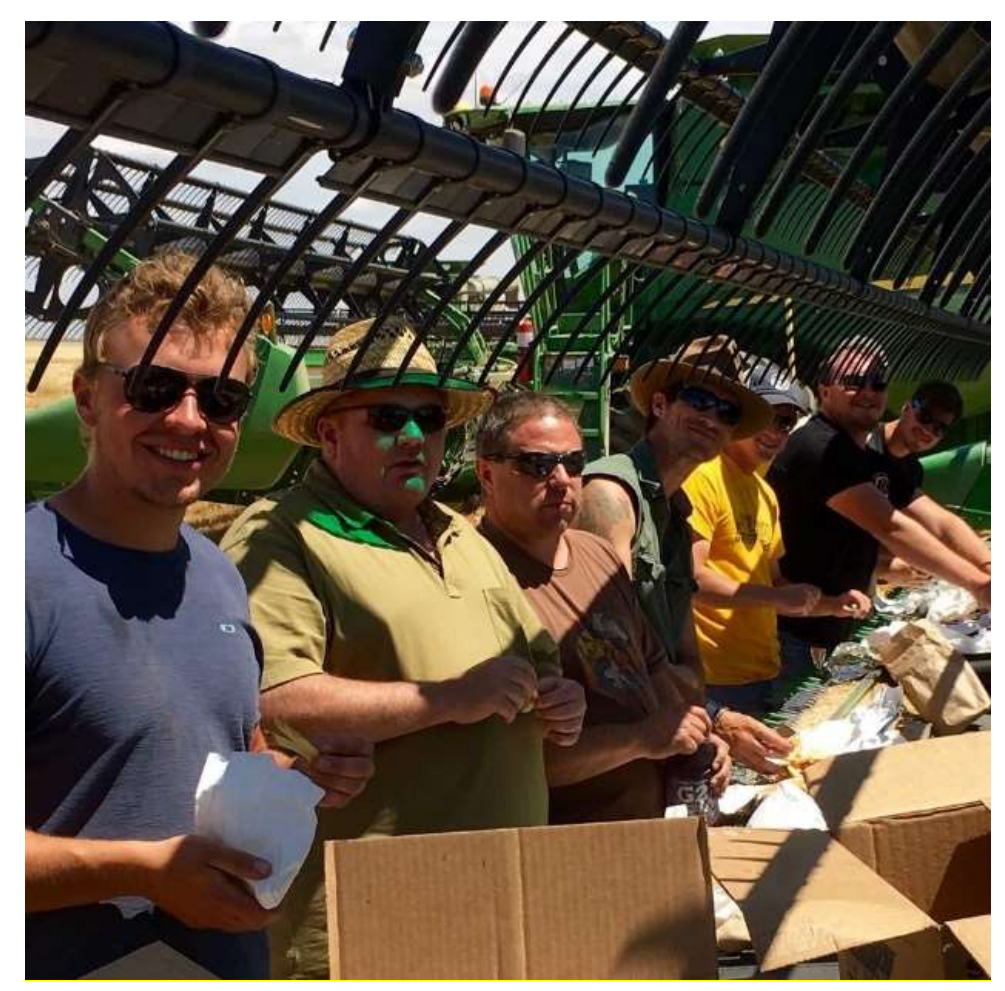

Fonte: Hendrik Albert Barkema.

O seguro da lavoura foi 52\% mais caro no Kansas que no Paraná. Contudo, ao fechar os custos variáveis, verificou-se que produzir milho no Brasil é mais caro que nos EUA. $\mathrm{O}$ maior gasto em terras brasileiras com sementes, adubos e agrotóxicos encareceu a lavoura em $53 \%$ em comparação com o estado estadunidense.

Os custos fixos, envolvendo os itens aluguel da terra e custos indiretos, foram maiores na agricultura norte-americana que na brasileira. Todavia, tal fator não foi preponderante no resultado final, ficando o custo total no Brasil em R\$3.152,69 e nos EUA em R\$2.422,44 por hectare, o que representa $30 \%$ mais de desembolso de recursos para conduzir a cultura do milho no Paraná que no Kansas. 
Tabela 5 - Custos da produção do milho (Zea mays) cultivada no estado do Paraná (Brasil), safra 2016/17.

\begin{tabular}{|c|c|c|c|c|c|}
\hline \multirow{2}{*}{\multicolumn{2}{|c|}{ Descrição }} & \multirow{2}{*}{$\begin{array}{c}\text { Quantidade } \\
\mathrm{kg} \mathrm{ha}^{-1}\end{array}$} & \multicolumn{2}{|c|}{ Preço $^{4}$} & \multirow{2}{*}{$\begin{array}{c}\text { Participação } \\
\%\end{array}$} \\
\hline & & & R\$ ha ${ }^{-1}$ & US\$ ha' & \\
\hline \multicolumn{2}{|l|}{ Sementes } & 26,0 & 515,84 & 147,81 & 16,4 \\
\hline & NPK semeadura ${ }^{1}$ & 300,0 & 429,64 & 123,11 & 13,6 \\
\hline \multirow[t]{2}{*}{ Adubos } & $\mathrm{NPK}^{2}$ & 350,0 & 401,60 & 115,07 & 12,7 \\
\hline & Nitrogênio ${ }^{3}$ & 160,0 & 163,86 & 46,95 & 5,2 \\
\hline \multicolumn{2}{|c|}{ Agrotóxicos } & - & 543,07 & 155,61 & 17,2 \\
\hline \multicolumn{2}{|c|}{ Semeadura (operação) } & - & 129,01 & 36,97 & 4,1 \\
\hline \multicolumn{2}{|c|}{ Pulverização (operação) } & - & 77,00 & 22,06 & 2,4 \\
\hline \multicolumn{2}{|l|}{ Colheita } & - & 258,10 & 73,95 & 8,2 \\
\hline \multicolumn{2}{|c|}{ Seguro da lavoura } & - & 146,99 & 42,12 & 4,7 \\
\hline \multicolumn{2}{|c|}{ Custos Variáveis } & - & $2.665,11$ & 763,64 & 84,5 \\
\hline \multicolumn{2}{|c|}{ Aluguel da terra } & - & 329,33 & 94,36 & 10,4 \\
\hline \multicolumn{2}{|c|}{ Custos indiretos ${ }^{4}$} & - & 158,25 & 45,34 & 5,0 \\
\hline \multicolumn{2}{|c|}{ Custos fixos } & - & 487,58 & 139,71 & 15,5 \\
\hline \multicolumn{2}{|c|}{ Custo Total } & - & $3.152,69$ & 903,35 & 100,0 \\
\hline
\end{tabular}

${ }^{1}$ Combinação de nitrogênio (N), fósforo (P) e potássio (K) na formulação (14-34-00).

${ }^{2}$ Combinação de nitrogênio $(\mathrm{N})$, fósforo $(\mathrm{P})$ e potássio (K) na formulação (21-00-20).

${ }^{3}$ Ureia $(45 \% \mathrm{~N})$.

${ }^{4}$ Inclui mão de obra contratada, seguro da fazenda, reparos, depreciação, benfeitorias etc.

${ }^{5}$ Cotação do dólar em 05/12/2016 - US\$ $1,00=\mathrm{R} \$ 3,49$.

Contudo, o maior investimento em sementes, adubação e controle de organismos não desejados na lavoura compensou os agricultores brasileiros com produtividade do milho $84 \%$ maior que a norte-americana (Tabela 6). Observa-se que a região do Kansas apresenta baixa precipitação (menos de $600 \mathrm{~mm}$ de chuva no ano), o que limita a produtividade da localidade, ficando abaixo da média nacional (USDA, 2017). Ao contrário, o município de Carambeí, na região dos Campos 
Gerais, no estado do Paraná, é reconhecido com destaque na produção de milho em terras brasileiras, ficando com o dobro da produtividade média nacional (CONAB, 2017).

Tabela 6 - Lucro pela produção do milho (Zea mays) cultivada no estado de Kansas (EUA) e Paraná (Brasil), safra 2016.

\begin{tabular}{|c|c|c|c|c|c|}
\hline \multirow{2}{*}{ País } & \multirow{2}{*}{$\begin{array}{l}\text { Produtividade } \\
\qquad\left(\mathrm{kg} \mathrm{ha}^{-1}\right)\end{array}$} & \multirow{2}{*}{$\begin{array}{c}\text { Receita (R\$ } \\
\left.h^{-1}\right)^{1}\end{array}$} & \multirow{2}{*}{$\begin{array}{l}\text { Custo produção (R\$ } \\
\left.\qquad \mathrm{ha}^{-1}\right)\end{array}$} & \multicolumn{2}{|c|}{ Lucro } \\
\hline & & & & $\left(\mathrm{R} \$ \mathrm{ha}^{-1}\right)$ & $\left(\mathrm{US} \$ \mathrm{ha}^{-1}\right)^{2}$ \\
\hline EUA & 6.052 & $2.711,30$ & $2.422,44$ & 288,86 & 82,77 \\
\hline Brasil & 11.114 & $5.408,81$ & $3.152,69$ & $2.256,12$ & 646,45 \\
\hline
\end{tabular}

${ }^{1}$ Preço pago por tonelada de milho nos EUA em R $\$ 448,00$ e no Brasil por R $\$ 486,67$.

${ }^{2}$ Cotação do dólar em 05/12/2012 - US\$ 1,00 = R \$3,49.

Como o estado do Paraná está mais perto de portos que o do Kansas, o milho pode ser vendido com $8,6 \%$ mais ganho no Brasil. Tal vantagem geográfica rentabiliza a comunidade brasileira mesmo em comparação com outras regiões do país com dimensões continentais.

A atividade foi lucrativa em ambas as comunidades avaliadas. O custo de $30 \%$ a mais no Brasil foi compensado pela produtividade e maior preço do produto. Por conseguinte, o lucro por hectare foi de $\mathrm{R} \$ 288,86$ nos EUA e $\mathrm{R} \$ 2.256,12$ no Brasil. As condições agroclimáticas levaram o agricultor paranaense a obter ganhos 7,8 vezes maiores que os produtores do Kansas, denotando a vocação agrícola da região.

Através de relatórios e apresentações dos dados levantados em reuniões com os envolvidos no projeto do The Ohio Program, houve uma análise da atividade por mais de 100 pessoas. As particularidades locais na produção das culturas e a questão macro da política agrícola de cada país foram o destaque no debate dos dados apresentados. Ressaltou-se a vocação agrícola do Brasil e sua competitividade no mercado internacional. A troca de informações com a comparação da condução das culturas em ambos os países em estudo possibilitou aos agricultores avaliarem pontos a serem melhorados no manejo de canola e trigo.

Com o envolvimento de comunidades agrícolas nos EUA e Brasil, a atividade contempla o princípio da indissociabilidade das atividades de ensino, pesquisa e extensão como fator fundamental no fazer acadêmico (ERI, 2019; GARCIA et al., 2019; SANTOS et al., 2016). Além dos desafios de extensão universitária impostos aos acadêmicos envolvidos no processo, destacadas por Oliveira et al. (2016), em seu estudo, na atividade desenvolvida em outro país está a barreira da comunicação por outro idioma, que foi superada com louvor pelos alunos comprometidos em tal atividade.

Com o detalhamento de toda a cadeia produtiva da canola e do milho em duas potências mundiais na produção de grãos, atingem-se os objetivos da extensão universitária, em que todos se beneficiam das ações - alunos e comunidade -, contribuindo para o desenvolvimento 
sustentável em diferentes esferas do conhecimento (NEVES et al., 2019). Destaca-se que tal atividade foi desenvolvida no complexo meio rural, onde Schlindwein et al. (2015) ressaltam a necessidade da extensão rural que contemple as peculiaridades do meio agropecuário.

\section{Conclusão}

O custo e a produtividade da canola foram maiores nos EUA, contudo, o lucro mais elevado foi alcançado em terras brasileiras. Em se tratando de milho, o custo, produtividade e lucro forma mais elevados no Brasil. A análise dos dados por mais de 100 pessoas envolvidas (agricultores, estudantes e professores) no projeto do The Ohio Program destaca a necessidade da extensão rural que contemple as peculiaridades do meio agropecuário, superando barreiras geográficas e de idiomas.

\section{Referências}

BERNARDI, A.C.C.; BETTIOL, G.M.; GREGO, C.R.; ANDRADE, R.G.; RABELLO, L.M.; INAMASU, R.Y. Ferramentas de agricultura de precisão como auxílio ao manejo da fertilidade do solo. Cadernos de Ciência \& Tecnologia, v. 32, n.1/2, p. 205-221, 2015.

CONAB - Companhia Nacional de Abastecimento. Acompanhamento de safra brasileira de grãos, segundo levantamento, novembro 2012. Disponível em:

$<$ http://www.conab.gov.br/OlalaCMS/uploads/arquivos/12_11_08_09_10_48_boletim_port ugues_novembro_2012.pdf>. Acesso em: 04 dez. 2012.

CONAB - Companhia Nacional de Abastecimento. Acompanhamento de safra brasileira de grãos, oitavo levantamento, maio 2017. Disponível em:

$<\mathrm{http}$ //www.conab.gov.br/OlalaCMS/uploads/arquivos/17_05_12_10_37_57_boletim_grao s_maio_2017.pdf >. Acesso em: 20 nov. 2017.

EMBRAPA - Empresa Brasileira de Pesquisa Agropecuária. Caracterização geral do processo produtivo agrícola de canola. Disponível em:

$<$ http://www.cnpt.embrapa.br/biblio/do/p_do118_8.htm>. Acesso em: 19 abr. 2019.

ERI - Escritório de Relações Internacionais, da Universidade Estadual de Ponta Grossa (UEPG). The Ohio Program. Disponível em: $<$ https://www3.uepg.br/eri/the-ohioprogram>. Acesso em: 9 out. 2019. 
GARCIA, L.C.; FERREIRA, A.Z.; FERREIRA, B.Z.; ROCHINSKI, L.V.; SANTOS, A.L.; WEIRICH NETO, P.H.; ROCHA, C.H.; GOMES, J.A.; SOUZA, N.M.; ZENY, E.P. Labor remuneration in the production of ornamental plants. International Journal of Advanced Engineering Research and Science, v. 6, n. 4, p. 185-189, 2019. DOI:

10.22161/ijaers.6.4.22.

KAEFER, J.E.; GUIMARÃES, V.F.; RICHART, A.; TOMM, G.O.; MÜLLER, A.L. Produtividade de grãos e componentes de produção da canola de acordo com fontes e doses de nitrogênio. Pesquisa Agropecuária Brasileira, v. 49, n. 4, p. 273-280, 2014. DOI: 10.1590/S0100-204X2014000400005

MAINARDES, E. L.; GARCIA, L. C.; WEIRICH NETO, P. H.; ROCHA, C. H.; INAGAKI, T.; SOUZA, N. M.; MAZER, G. P.; GOMES, J. A.; MOURA, I. C. F.; ZENY, E. P. Economic feasibility of canola production in the region of Campos Gerais, Paraná, Brazil. American Journal of Plant Sciences, v. 9, n. 1, p. 958-965, 2018. DOI: 10.4236/ajps.2018.95073.

NEVES, G.P.A.; MENDES, J.; GARCIA, L. C.; MELO, M. H.; MIRANDA, E. L.; GOMES, J. A.; CHARNOBAY, A. C. R.; FARIAS, A.; BERNARDI, W. K.;

CALDERARI, N. Levantamento na área rural dos Campos Gerais (PR) sobre o impacto do manejo outono/inverno na proliferação da doença de plantas mofo-branco. Revista Conexão UEPG, v. 15, p. 199-203, 2019. DOI: 10.5212/Rev.Conexao.v.15.i2.0011.

OLIVEIRA, F.L.B.; ALMEIDA JÚNIOR, J.J.; SILVA, M.L.P. Percepção dos acadêmicos em relação às dificuldades no desenvolvimento de projetos de extensão universitária. Revista Ciência em Extensão, v. 12, n. 2, p. 18-25, 2016.

SANTOS, J.; ROCHA, B.; PASSAGLIO, K. Extensão universitária e formação no ensino superior. Revista Brasileira de Extensão Universitária, v. 7, n. 1, p. 23-28, 2016.

SCHLINDWEIN, M. M.; SANGALLI, A. R.; RODE, M.; STEFANELLO, V. M. R. Pesquisa e extensão: a união de esforços para o enfrentamento dos desafios do desenvolvimento rural. Redes, v. 20, n. 3, p. 203-225, 2015. DOI:

10.17058/redes.v20i3.5225.

USDA - United States Department of Agriculture. History canola. Disponível em: $<$ http://www.ers.usda.gov/topics/crops/soybeans-oil-crops/canola.aspx\#crophistory $>$. Acesso em: 05 dez. 2012. 
USDA - United States Department of Agriculture. Corn Data: yearbook tables. Disponível em: <https://www.nass.usda.gov/Newsroom/2017/01_12_2017.php >. Acesso em: 01 nov. 2017. WANASUNDARA, J.P.D.; MCINTOSH,

WANASUNDARA, J.P.D.; MCINTOSH, T.C.; PERERA, S.P.; WITHANA-GAMAGE, T.S.; MITRA, P. Canola/rapeseed protein-functionality and nutrition. OCL, v. 23, n. 4, p. 407-422. 2016. DOI: 10.1051/oc1/2016028. 